\title{
Erratum to: Pilot early intervention antenatal group program for pregnant women with anxiety and depression
}

\author{
Naomi Thomas • Angela Komiti • Fiona Judd
}

Published online: 4 September 2014

(C) Springer-Verlag Wien 2014

\section{Erratum to: Arch Womens Ment Health}

DOI 10.1007/s00737-014-0447-2

Figure 1 in the original version of this article was incorrectly placed in the method section with the description of the EPDS rather than as a part of the results of the study. The paragraph relating to the findings depicted in Figure 1 was unfortunately deleted from the results section. All information shown in the figure was correct. The description of the results in Figure 1 appears below.

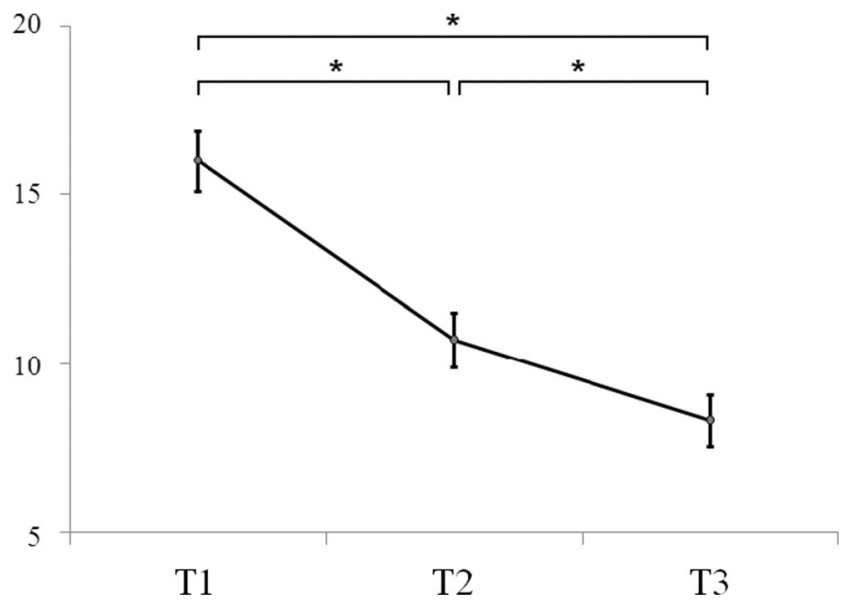

The online version of the original article can be found at http://dx.doi.org/ 10.1007/s00737-014-0447-2.

N. Thomas $\cdot$ A. Komiti $\cdot$ F. Judd $(\bowtie)$

Centre for Women's Mental Health, Royal Women's Hospital,

Locked Bag 300, Parkville, VIC, Australia

e-mail: fionakj@unimelb.edu.au

A. Komiti $\cdot$ F. Judd

Department of Psychiatry, University of Melbourne, Parkville,

VIC 3052, Australia
Figure 1 shows the change in mean EPDS depression scores from pre-treatment $(M=16.2, S D=5.0)$, post-treatment $(M=10.5, S D=4.0)$ and at two months postpartum follow up $(M=8.3, S D=4.2)$. Figure 1 shows a significant change in depression scores between pretreatment and post-treatment $(p<.001)$ and pre-treatment and two-months postpartum $(p<.001)$. A significant difference was also observed between post-treatment (T2) and two month postpartum follow-up (T3) depression scores $(p=.006)$. 